\title{
Active case finding of tuberculosis in Europe: a Tuberculosis Network European Trials Group (TBNET) survey
}

\author{
G.H. Bothamley*, L. Ditiü , G.B. Migliori ${ }^{\mp}$, C. Lange $^{+}$and TBNET contributors ${ }^{\S}$
}

ABSTRACT: Tuberculosis control depends on successful case finding and treatment of individuals infected with Mycobacterium tuberculosis. Passive case finding is widely practised: the present study aims to ascertain the consensus and possible improvements in active case finding across Europe.

Recommendations from national guidelines were collected from 50 countries of the World Health Organization European region using a standard questionnaire.

Contacts are universally screened for active tuberculosis and latent tuberculosis infection (LTBI). Most countries ( $>70 \%$ ) screen those with HIV infection, prisoners and in-patient contacts. Screening of immigrants is related to their contribution to national rates of tuberculosis. Only 25 $(50 \%)$ out of 50 advise a request for symptoms in their guidelines. A total of 36 (72\%) out of 50 countries recommend sputum examination for those with a persistent cough; 13 countries do not, even if the chest radiograph suggests tuberculosis. Nearly all countries (49 out of 50) use tuberculin skin testing (TST); 27 (54\%) out of 50 countries also perform chest radiography irrespective of the TST result. Interpretation of the TST varies widely. All countries use 6-9 months of isoniazid for treatment of LTBI, with an estimated median (range) uptake of 55\% (5-92.5\%).

Symptoms and sputum examination could be used more widely when screening for active tuberculosis. Treatment of latent tuberculosis infection might be better focused by targeted use of interferon- $\gamma$ release assays.

KEYWORDS: Active case finding, contacts, Europe, screening, tuberculosis

espite investment towards tuberculosis (TB) control in Europe, the incidence of TB has increased between 2000 and 2005 in countries such as Norway, the UK and Ireland, in addition to Romania, Turkey, Macedonia and Bulgaria and all except Kyrgyzstan and Turkmenistan in the eastern part of the World Health Organization (WHO) European region [1]. Passive case finding is standard and consistent with the WHO-recommended Stop TB Strategy [2]. Active case finding includes all methods for the identification and then treatment of those with TB who have not reported to the healthcare system of their own accord. The aim is to reduce the transmission of $\mathrm{TB}$ by screening high-risk populations (i.e. those at an increased risk of exposure to TB infection, most notably contacts of infectious cases) and to detect and treat active disease earlier than would otherwise occur $[3,4]$. At the same time, latent tuberculosis infection (LTBI) may be detected and treated, and thereby prevent the later development of active TB.

In 2006, the Tuberculosis Network European Trials Group (TBNET) was established in order to conduct clinical trials and surveys on $\mathrm{TB}$ in Europe. The present survey was undertaken within the TBNET to determine whether national guidelines or policies within Europe recommend screening of the same high-risk groups, use the same methods and locations for screening and whether the nature and estimated uptake of preventive treatment is uniform. The present authors expected to see differences related to local epidemiology, such as screening for migrants, only in those countries where immigrants represent a

This article has supplementary material accessible from www.erj.ersjournals.com

Earn CME accreditation by answering questions about this article. You will find these at the back of the printed copy of this issue or online at http://www.erj.ersjournals.com/current.shtml

AFFILIATIONS

*North East London Tuberculosis Network, Homerton University Hospital, London, UK.

\#Tuberculosis Control, World Health Organization Regional Office for Europe, Scherfigsvei, Copenhagen, Denmark.

"World Health Organization

Collaborating Centre for Tuberculosis and Lung Diseases, Fondazione $\mathrm{S}$

Maugeri, Care and Research Institute, Tradate, Italy.

+Division of Clinical Infectious Diseases, Research Center Borstel, Borstel, Germany.

${ }^{\S}$ For a full list of TBNET contributors see the Acknowledgements section.

CORRESPONDENCE

G.H. Bothamley NE London TB Network Homerton University Hospital London E9 6SR

UK

Fax: 442085107731

E-mail: graham.bothamley@

homerton.nhs.uk

Received:

January 242008

Accepted after revision:

May 232008

SUPPORT STATEMENT

This work was supported by the NHS Culyer allocation, UK.

STATEMENT OF INTEREST

None declared. 
significant proportion of cases of TB [5]. Discrepancies between local epidemiology and national guidelines might encourage the redirection of resources to improve the treatment success rate of active TB, which is currently less than the World Health Assembly target of $85 \%$. The current authors' aim was to help clinicians and inform national committees creating guidelines of: 1) consensus, which would define the minimum standard of active case finding for TB across Europe; 2) variations, affected by local epidemiology; 3) guidelines of historical or sociological significance, that are no longer necessary; and 4) differences in the treatment of LTBI.

\section{METHODS}

\section{The questionnaire}

A questionnaire was developed consisting of three sections: who should be screened; what screening methods are used; and the nature of preventive treatment (see online supplementary material). The questions regarding a positive tuberculin skin test (TST) were based on the American Thoracic Society guidelines interpretation of the available evidence [6], whereby the clinical circumstances determine the cut-off value. Questions included bacillus Calmette-Guérin (BCG) vaccination policy as a check for replies to TST screening. Locations for screening were requested as an indication of the variety of screening programmes available. Questionnaires were in English and Russian; the Russian version was re-translated into English to confirm accuracy of translation.

\section{Data collection}

Representatives from each European country were selected on the basis of their official position in their own country's TB programme: all were participants in the TBNET, EuroTB (a WHO collaborating centre for the surveillance of $\mathrm{TB}$ in Europe) correspondents and/or members of the TB section of the European Respiratory Society (ERS). They were required to have sufficient command of English or Russian to understand the questionnaire, to have access to their national guidelines and to answer the questionnaire using these guidelines. The only personal opinion that was invited was their estimate of the uptake of LTBI treatment compared with the number eligible under their national guidelines. The questionnaire was returned to each respondent $1 \mathrm{yr}$ after data collection; the respondent was then required to confirm that they had answered each question from their national guidelines and that no personal opinions were expressed, except for the estimate of uptake of LTBI treatment. Any corrections made at this stage were then incorporated into the final manuscript.

All definitions used (except otherwise mentioned) were derived from WHO documents and ERS guidelines [2-4, 7]. Epidemiological data for TB in Europe were taken from the EuroTB website [8]. These included: the proportion of cases due to foreign-born transmission; the most recent cure/ completion rate; and the proportion with concurrent HIV infection.

\section{RESULTS}

\section{Respondents}

Replies were obtained from 50 out of 53 countries of the WHO European region (all countries except Monaco, San Marino and Andorra; table 1). Two countries have no national guidelines for TB and each gave an expert opinion on current practice
(Greece) or guidelines to be issued in late 2008 (Austria). Five $(10 \%)$ countries had two respondents: in the first survey, replies from four countries were identical, but one differed by 27 out of 65 items; differences were resolved by referral to a TB expert from that country. A total of $12(24 \%)$ respondents provided a copy of national guidelines (eight with a translation of the relevant portions in English), which were used to check the accuracy of the replies; no discrepancies were identified. Eight countries provided modifications when prompted $1 \mathrm{yr}$ later to reassess their responses against national guidelines and exclude personal opinion. In one, there were nine changes due to revised guidelines (Montenegro), another added missing data (Tajikistan) and the remaining six countries made one, two or three changes (two, three and one countries, respectively).

\section{Contacts}

Six $(12 \%)$ out of 50 countries limit screening to contacts of sputum smear-positive pulmonary TB (table 1). The remaining countries are equally divided between those who screen contacts of just pulmonary or all TB cases.

\section{Immigrants}

In total, 28 (56\%) countries screen immigrants. In 16 (32\%) out of 50 countries, foreign-born persons contribute $>40 \%$ of all TB and only two in this category (Denmark and Austria) do not carry out screening of new immigrants. In countries with a moderate contribution (11-40\%) of immigrants to TB (seven (14 $\%$ ) out of 50), three have no screening programme, two carry out selective screening and two screen all new entrants. Six countries with $\leqslant 1 \%$ and four countries with $<5 \%$ of TB due to foreign-born subjects have screening programmes for immigrants.

\section{Other high-risk groups}

Most countries screen for TB in those who are HIV positive (42 $(84 \%)$ out of 50$)$, prisoners $(37(74 \%)$ out of 50$)$ and hospital contacts of in-patients (35 (70\%) out of 50). In 32 (64\%) out of 50 countries, information on HIV co-infection was available: two out of 16 countries with an estimated co-infection rate of $>5 \%$ and two out of 13 countries with a rate of $1-5 \%$ have no policy for screening patients with HIV infection for TB. Screening of laboratory staff (33 (66\%) out of 50 countries), the homeless (24 $(48 \%)$ out of 50$)$, teachers $(19(38 \%)$ out of 50$)$ and the elderly in long-term care facilities (16 (32\%) out of 50) occurs less often. Three replies mention screening for TB before the use of antitumour necrosis factor (TNF) treatments and in those whose immunity is depressed for any reason. Individual countries also screen intravenous drug users (Belgium, Macedonia, Portugal, Serbia), selected Roma people (Macedonia, Serbia), the mentally ill (Macedonia, Serbia), prostitutes (Austria) and food handlers (Moldova, Poland).

\section{Process of screening}

One-half of the countries specify questioning for symptoms of TB in those who are screened. Almost three-quarters (36 (72\%) out of 50) ask for a sputum smear where someone reports cough lasting $>3$ weeks. Only one country screens all those at risk of TB with chest radiography alone, while the majority (49 out of 50) use TST and $27(55 \%)$ of these obtain a chest radiograph irrespective of the TST result. A total of $12(24 \%)$ 
TABLE 1 Who is screened for tuberculosis (TB)?

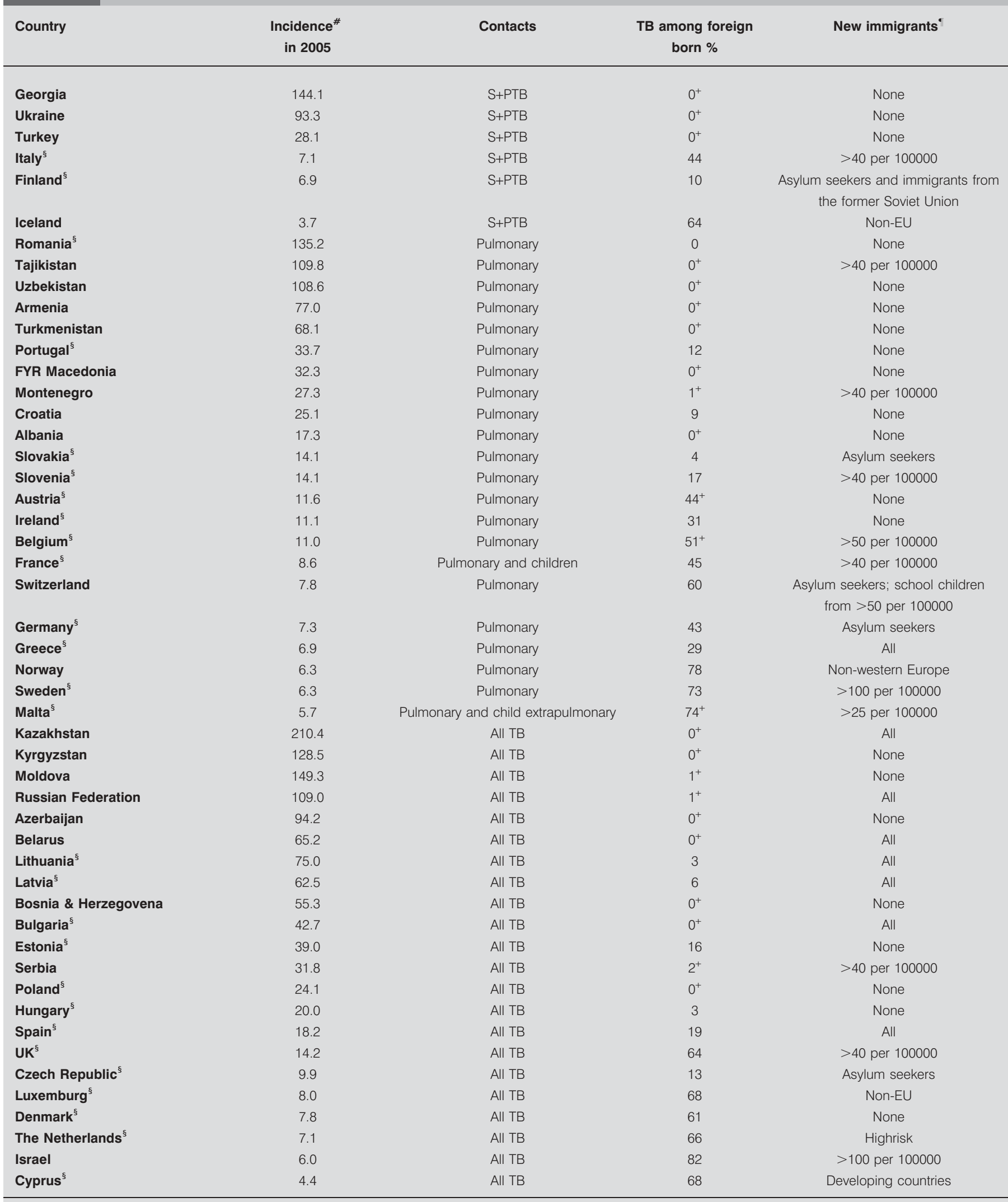

S+PTB: sputum smear-positive pulmonary TB. ${ }^{*}$ : per 10,000 of the population; $"$ : where rates are shown immigrant screening is mandated/recommended if recent TB notification rates in the country of origin exceed this threshold; ${ }^{+}$: citizenship rather than place of birth; ${ }^{\text {s: }}$ European Union member. 
countries out of 50 have access to mass radiography screening and seven $(14 \%)$ out of 50 recommend its use in guidelines. Need for sputum examination is not stipulated by guidelines in $13(26 \%)$ out of 50 countries when a chest radiograph suggests TB. Legal provisions for screening individuals for TB are available in $20(40 \%)$ out of 50 countries, but comments as to how often this was used were not invited.

Many guidelines recommend screening for active TB in a larger group than that eligible for LTBI treatment. In 22 (44\%) out of 50 countries, guidelines recommend TST in the same population that will receive LTBI treatment if LTBI is present (one for 05 yrs of age; 12 for age $0-16$ yrs, five for those up to 35 yrs of age; and four for $>35$ yrs of age), using other tests to exclude active TB. The median estimated uptake of LTBI treatment in these countries is $55 \%$ (data available for 17 countries; range $10-90 \%$ ), but lower $(40 \%)$ in countries where TST is used indiscriminately (data available for 14 countries; range 5-92.5\%).

Interpretation of the TST varies widely across the European region (table 2). In 28 (56\%) out of 50 countries, interpretation of the TST is not modified according to the presence or absence of a BCG scar; two comment that BCG vaccination is compulsory and five have no BCG programme. In the latter five countries, immigration contributes significantly to the incidence of TB (median 44\% (range 9-60\%)). Most countries set a positive TST for those with concurrent HIV infection $(70 \%)$ and BCG-negative contacts (17 out of 17 where mentioned) at $5 \mathrm{~mm}$. Induration of $10 \mathrm{~mm}$ was the commonest cut-off value for healthy subjects at risk of TB (25 (54\%) out of $47)$, immigrants (20 (41\%) out of 49 ) and BCG-positive contacts (nine (53\%) out of 17 where specified).

All countries offer LTBI treatment consisting of either 6 or 9 months of isoniazid. Alternative regimens are offered in 13 (26\%) out of 50 countries in specified circumstances: 11 offer 3 months of rifampicin and isoniazid, eight offer 4 months of rifampicin and four offer 2 months of rifampicin and pyrazinamide. One country (Portugal) permits the use of 2 months of rifampicin, isoniazid and pyrazinamide.

LTBI treatment is required in $26(52 \%)$ out of 50 countries, while radiographic follow-up is recorded as an option in 27
(54\%) out of 50 countries. Most countries will recommend LTBI treatment for HIV-positive contacts of patients with sputum smear-positive pulmonary TB (40 (80\%) out of 50$)$ and for babies born to mothers with pulmonary TB (42 (84\%) out of 50; one only if the mother is not on treatment at the time of delivery).

\section{DISCUSSION}

The present study is the first survey of national guidelines comparing screening for active and latent TB across the WHO European region. There is a general consensus that advocates screening of TB contacts and offers treatment for individuals with LTBI. Discrepancies between a low detection rate and excessive screening suggest that some programmes could be improved.

\section{Priorities in contact tracing}

The two main reasons for contact tracing are identification of active cases and those infected who are at risk of developing active TB later in life. Most patients with active TB have symptoms, such as cough, fever, night sweats and weight loss [9], yet only half of European countries recommend asking for symptoms of active TB in those who are screened. Indeed, a productive cough for $>3$ weeks can be used as a simple tool to refine the investigation of those with suspected contagious TB $[10,11]$. The evidence supports both screening of contacts of only pulmonary TB (especially sputum smear-positive TB, which is the most contagious form) $[12,13]$ and of nonpulmonary $\mathrm{TB}$, the latter on the grounds that they represent an especially high-risk group [13-17]. Indeed, DNA fingerprinting has shown that strains of Mycobacterium tuberculosis found in contacts may differ from, rather than be the same as, the strain obtained from the index case [18, 19].

The recognition of LTBI before developing TB is uncertain. A positive TST is most frequent in contacts of those with smearpositive TB $[12,20]$. Even when the index has nonpulmonary TB, a positive TST is still more common than in any of the other high-risk groups screened [13]. Therefore, the current authors advocate that after effective treatment of active TB is established, contacts of all TB patients are screened before any other high-risk group.

\begin{tabular}{|c|c|c|c|c|c|}
\hline \multirow[t]{2}{*}{ Group } & \multirow{2}{*}{$\begin{array}{l}\text { Screening } \\
\text { undertaken }\end{array}$} & \multicolumn{3}{|c|}{ Tuberculin cut-off value } & \multirow[t]{2}{*}{ No guideline } \\
\hline & & $5 \mathrm{~mm}$ & $10 \mathrm{~mm}$ & $15 \mathrm{~mm}$ & \\
\hline \multicolumn{6}{|l|}{ Contacts } \\
\hline BCG negative & 22 & 21 & 1 & 0 & 0 \\
\hline BCG positive & 22 & 0 & 14 & 8 & 0 \\
\hline Immigrants & 27 & 1 & 20 & 1 & 5 \\
\hline Healthy persons at risk of TB & 49 & 2 & 25 & 2 & 20 \\
\hline HIV positive & 40 & 35 & 1 & 2 & 2 \\
\hline
\end{tabular}

Data are presented as number of countries. BCG: bacillus Galmette-Guérin 


\section{Other high-risk groups}

Active screening is expensive, and indiscriminate screening is inefficient [5]. Several countries had high TB incidence and poor treatment success rates despite extensive screening; higher efficacy and lower cost programmes seem feasible [4, 21]. However, mathematical models suggest that active case finding can have a significant impact on the incidence of TB [22], especially in those co-infected with HIV [23]. There is a general consensus supporting the screening of patients with HIV infection for TB $[1,7,13,24]$. Treatment of LTBI reduces the risk of active tuberculosis in HIV-positive individuals with positive TSTs, in countries with high [25] and low [26] incidences of $\mathrm{TB}$, although the absolute number of prevented cases in low incidence countries is small. This policy is not yet implemented widely, especially in countries from the Eastern European region, where the TB/HIV co-infection rate is increasing. The newer $\mathrm{T}$-cell interferon- $\gamma$ release assays (TIGRAs) may be more helpful than the TST in detecting LTBI in individuals infected with HIV [27].

A survey of several European countries has confirmed that the prevalence of TB in prisons is nearly 100-fold greater than in the general population [28], especially in those subjects with HIV infection [29]. The risk of TB in i.v. drug users, prostitutes and those with mental illness is also associated with concurrent HIV infection [30-32]. TB is spread by aerosols and not by food; the inclusion of food handlers in $\mathrm{TB}$ guidelines is therefore a historical anomaly [33].

The problem of the effectiveness of active case finding has particularly exercised national experts in regard to immigrant screening. While immigration can account for a significant proportion of a country's TB notifications, the number of immigrants can be so large that the likelihood of finding a case of TB for an individual clinic or entry point to the country can be extremely small [34]. However, the yield may vary depending on the subgroup of immigrants screened. For example, in Belgium, the incidence of TB was significantly higher in asylum seekers than in other immigrants [35]. In Israel, Ethiopians and those from the former Soviet Union have more intensive screening [36]. Many countries have adopted a selective screening policy based on incidence of TB in the country of origin (table 1). Most immigrants are healthy when they arrive and, therefore, screening by chest radiography is of little benefit. National surveys have shown that most immigrants present with active TB $>5$ yrs after arrival [37, 38]. Programmes with continued screening of immigrants, even on a voluntary basis, can be effective [39], but most transmission is still from individuals who do not attend screening [40]. Many have argued that the detection of LTBI can make screening for TB among immigrants cost effective, but only if treatment of LTBI is completed and set-up and administrative costs are excluded [34]. Where multidrug-resistant and extensively drug-resistant TB is likely [41, 42], screening can be cost effective in treating active disease and permitting follow-up to recognise the development of drug-resistant TB early [43] Selection of immigrants most likely to have TB (e.g. in deprived city areas) [44], or to adhere to treatment of LTBI [45] may be more effective than general screening.

\section{LTBI}

The average number of secondary TB cases acquired from a primary case is affected most by those who develop TB after a latent period [46]. Treatment of LTBI holds the greatest benefit in controlling TB after treatment of active, infectious cases. However, few contacts with positive TSTs are offered, and even fewer adhere to, treatment of LTBI [47].

TST is widely undertaken, but surveys to define the best cut-off point for discrimination between those most likely to develop disease and those in whom LTBI is unlikely are rare in Europe [48], with the best such survey being from Canada [49]. There is a general consensus that a TST induration diameter of $>5 \mathrm{~mm}$ should be the cut-off value for those without BCG vaccination or with HIV co-infection (table 2). However, in HIV infection anergy may be an all-or-none phenomenon, so that the size of induration is not helpful [50]. Most countries considered TST $>10 \mathrm{~mm}$ positive in those with a BCG vaccination, but a meta-analysis has suggested that $15 \mathrm{~mm}$ might be a better cut-off [51].

\section{TIGRA and LTBI}

Large longitudinal studies of TIGRAs have yet to define their role in assessing who will benefit from treatment of LTBI. However, contacts with a positive TIGRA may have a higher risk of developing TB than contacts with a positive TST [52]. As merely $1.7 \%$ of tuberculin-positive contacts develop active TB [53], the UK National Institute for Health and Clinical Excellence guidelines limit those offered treatment of LTBI by requiring a TST of $\geqslant 15 \mathrm{~mm}$ and a positive TIGRA [13]. Transient TIGRA responses have been observed in TSTnegative contacts, suggesting the possibility of resolving acute infection [54]. The use of a TIGRA should be prioritised to those most likely to benefit from treatment of LTBI (contacts aged $<16$ yrs, HIV co-infected individuals and those receiving anti-TNF treatment) [55].

\section{Treatment of LTBI}

Treatment of individuals with TST conversion is cost-effective and is important to decrease the global incidence of TB [55]. However, completion rates are unsatisfactory in the countries that were surveyed and the relative benefit of treatment of LTBI is very low (to prevent one case of active TB, 72 subjects (95\% confidence interval 50-143) need to be treated [53], although this is comparable to the benefit of secondary prevention in myocardial infarction [56]). Adherence is often as low as $11-30 \%[34,38,47]$. While the current authors cannot argue against the individual benefit of completing a course of treatment of LTBI, the public health benefit of the strategy relies critically on large acceptance and completion rates. Clearly, if treatment of LTBI is not going to be undertaken (e.g. where the risks from drug-induced hepatitis outweigh the benefits or indeed the individual does not agree to take any treatment after the risks have been explained clearly to them, unless follow-up is important as in the instance of contact with drug-resistant TB), then TST or TIGRA need not be performed and active TB should merely be excluded (e.g. by symptoms and sputum smear) at the first visit and by appropriate follow-up.

\section{Conclusion}

The minimum standard for active case finding is screening all contacts of patients with sputum smear-positive tuberculosis. In addition, screening contacts of those with tuberculosis but 
without a positive sputum smear and individuals with HIV infection is broadly supported. In order to improve the detection of active tuberculosis, symptoms should be sought and sputum sent for analysis from all those with an abnormal chest radiography suggestive of tuberculosis. Many guidelines could be improved by using T-cell interferon- $\gamma$ release assays to confirm latent tuberculosis infection and limit testing to those who would agree to be treated. Selective screening, especially of immigrants, should be guided by local epidemiology. While a 6-9 month regimen of isoniazid monotherapy is widely recommended for the treatment of latent tuberculosis infection in Europe, Mycobacterium tuberculosis resistance to isoniazid is increasing and alternative welltolerated short-term regimens need to be explored.

\section{ACKNOWLEDGEMENTS}

The TBNET contributors are as follows. Official national representative for EuroTB contributors: H. Hafizi (Tirana, Albania); N. Mezhlumyan (Yerevon, Armenia); S. Mamedova (Baku, Azerbaijan); M. Wanlin (Brussels, Belgium); H. Zutic (Sarajevo, Bosnia and Herzegovina); D. Stefanova (Sofia, Bulgaria); A. Simunovic (Zagreb, Croatia); C. Hadjianastassiou (Nicosia, Cyprus); D. Falzon (Saint-Maurice, France); A. Salakaia (Tbilisi, Georgia); S. Georgia (Athens, Greece); T. Blöndal (Rekjavik, Iceland); D. Chemtob (Jerusalem, Israel); B.K. Khasanovna (Almaty, Kazakhstan); A. Elmira (Bishkek, Kyrgystan); J. Leimans (Riga, Latvia); E. Davidaviciene (Vilnius, Lithuania); A. Vidoevska (Skopje, Macedonia); A.P. Asciak (Qormi, Malta); O. Bojovic (Niksic, Montenegro); B.A. Winje (Oslo, Norway); M. Korzeniewska (Warsaw, Poland); I. Solovic (Vysne Hagy, Slovakia); D. Erzen (Golnik, Slovenia); S. Saidaliev (Dushanbe, Tajikistan); D.M. Khaldurdyevna (Ashgabat, Turkmenistan); O. Sakalska (Kiev, Ukraine); and U.D. Djumabaevna (Tashkent, Uzbekistan).

Other TBNETcontributors: B. Schmidgruber (Vienna, Austria); O.M. Kalechitz (Minsk, Belarus); G. Vankersshaever (Brussels, Belgium); S. Kos (Mirosov, Czech Republic); P. Ravn (Herlev, Denmark); K. Kliiman (Tartu, Estonia); R. Ruohonen (Helsinki, Finland); H-P. Mallet (Paris, France); O. Bock-Hensley (Heidelberg, Germany); G. Loytzved (Würzburg, Germany); A. Somoskövi and I. Horvath (Budapest, Hungary); J. Keane (Dublin, Ireland); L.R. Codecasa (Milan, Italy); F. Chaussade (Luxembourg, Luxembourg); V. Soltan (Chisinau, Republic of Moldova); S. Arend (Leiden, the Netherlands); M. Villar (Amadora, Portugal); I. Husar and P Stoicescu (Bucharest, Romania); L. Rybka (Moscow, Russia); D. Pesut (Belgrade, Serbia); J.M. Garcia (Asturias, Spain); J. Bruchfeld and I. Julander (Stockholm, Sweden); J-P. Janssens (Geneva, Switzerland); and O. Ergonul (Istanbul, Turkey).

The authors thank R. Centis, Tradate, Italy, for her kind support and advice.

\section{REFERENCES}

1 World Health Organization. Global tuberculosis control: surveillance, planning, financing. Geneva, World Health Organization, 2007.
2 Hopewell PC, Pai M, Maher D, Uplekar M, Raviglione MC. International standards for tuberculosis care. Lancet Infect Dis 2006; 6: 710-725.

3 Migliori GB, Hopewell PC, Blasi F, Spanevello A, Raviglione MC. Improving the TB case management: the International Standards for Tuberculosis Care. Eur Respir J 2006; 28: 687-690.

4 Broekmans JF, Migliori GB, Rieder HL, et al. European framework for tuberculosis control and elimination in countries with low incidence. Recommendations of the World Health Organization (WHO) International Union against Tuberculosis and Lung Disease (IUATLD) and the Royal Netherlands Tuberculosis Association (KNCV) Working Group. Eur Respir J 2002; 19: 765-775.

5 Coker R, Bell A, Pitman R, et al. Tuberculosis screening in migrants in selected European countries shows wide disparities. Eur Respir J 2006; 27: 801-807.

6 American Thoracic Society. Diagnostic standards and classification of tuberculosis in adults and children. Am J Respir Crit Care Med 2000; 161: 1376-1395.

7 Clancy L, Rieder HL, Enarson DA, Spinaci S. Tuberculosis elimination in the countries of Europe and other industrialized countries. Eur Respir J 1991; 4: 1288-1295.

8 Surveillance of tuberculosis in Europe EuroTB. www.euroTB.org Stockholm/Geneva, European Centre for Disease Prevention and Control/World Health Organization European region.

9 Meijer J, Barnett GD, Kubik A, Styblo K. Identification of sources of infection. Bull Int Union Tuberc 1971; 45: 5-54.

10 Aluoch JA, Swai OB, Edwards EA, et al. Study of casefinding for pulmonary tuberculosis in outpatients complaining of chronic cough at a district hospital in Kenya. Am Rev Respir Dis 1984; 129: 915-920.

11 Golub JE, Mohan CI, Comstock GW, Chaisson RE. Active case finding of tuberculosis: historical perspective and future prospects. Int J Tuberc Lung Dis 2005; 9: 1183-1203.

12 Liippo KK, Kumala K, Tala EO. Focusing tuberculosis contact tracing by smear grading of index cases. Am Rev Respir Dis 1993; 148: 235-236.

13 National Collaborating Centre for Chronic Conditions. Tuberculosis: clinical diagnosis and management of tuberculosis, and measures for its prevention and control. London, Royal College of Physicians, 2006.

14 Becerra MC, Pachao-Torreblanca IF, Bayona J, et al. Expanding tuberculosis case detection by screening household contacts. Public Health Report 2005; 120: 271-277.

15 Irish C, Jolly E, Baker T. Contact tracing smear-positive and non-pulmonary tuberculosis in a high incidence area. Thorax 1997; 52: A34.

16 Ormerod LP. Results of tuberculosis contact tracing: Blackburn 1982-1990. Resp Med 1993; 87: 127-131.

17 Kumar S, Innes JA, Skinner C. Yield from tuberculosis contact tracing in Birmingham. Thorax 1992; 47: 875.

18 Van Deutekom H, Hoijng SP, de Haas PE, Langendam MW. Clustered tuberculosis cases: do they represent recent transmission and can they be detected earlier? Am J Resp Crit Care Med 2004; 169: 806-810.

19 Solsona J, Cayla JA, Verdu E, et al. Molecular and conventional epidemiology of tuberculosis in an inner city district. Int J Tuberc Lung Dis 2001; 5: 1159-1163. 
20 Rose C, Zerbe G, Lantz S, Bailey W. Establishing priority during investigation of tuberculosis contacts. Am Rev Respir Dis 1979; 119: 603-609.

21 Migliori GB, Khomenko AG, Punga VV, et al. Costeffectiveness analysis of tuberculosis control policies in Ivanovo Oblast, Russian Federation. Ivanovo Tuberculosis Project Study Group. Bull World Health Organ 1998; 76: 475-483.

22 Murray CJ, Salomon JA. Modeling the impact of global tuberculosis control strategies. Proc Natl Acad Sci USA 1998; 95: 13881-13886.

23 Currie CS, Williams BG, Cheng R, Dye C. Tuberculosis epidemics driven by HIV: is prevention better than cure? AIDS 2003; 17: 2501-2508.

24 Joint Tuberculosis Committee of the British Thoracic Society. Control and prevention of tuberculosis in the United Kingdom: Code of Practice 2000. Thorax 2000; 55: 887-901.

25 Whalen CC, Johnson JL, Okwera A, et al. A trial of three regimens to prevent tuberculosis in Ugandan adults infected with the human immunodeficiency virus. Uganda-Case Western Reserve University Research Collaboration. N Engl J Med 1997; 337: 801-808.

26 Elzi L, Schlegel M, Weber R, et al. Reducing tuberculosis incidence by tuberculin skin testing, preventive treatment, and antiretroviral therapy in an area of low tuberculosis transmission. Clin Infect Dis 2007; 44: 94-102.

27 Luetkemayer AF, Charlebois ED, Flores LL, et al. Comparison of an interferon- $\gamma$ release assay with tuberculin skin testing in HIV-infected individuals. Am J Respir Crit Care Med 2007; 175: 737-742.

28 Aerts A, Hauer B, Wanlin M, Veen J. Tuberculosis and tuberculosis control in European prisons. Int J Tuberc Lung Dis 2006; 10: 1215-1223.

29 Drobniewski FA, Balabanova YM, Ruddy MC, et al. Tuberculosis, HIV seroprevalence and intravenous drug abuse in prisoners. Eur Respir J 2005; 26: 298-304.

30 March JC, Oviedo-Joekes E, Romero M. Factors associated with reported hepatitis $\mathrm{C}$ and HIV among injecting drug users in ten European cities. Enferm Infect Microbiol Clin 2007; 25: 91-97.

31 Fleming MF, Krupitsky E, Tsoy M, et al. Alcohol and drug use disorders, HIV status and drug resistance in a sample of Russian TB patients. Int J Tuberc Lung Dis 2006; 10: 565-570.

32 Pesut D. Active case detection for tuberculosis in risk groups in Serbia. Med Pregl 2004; 57: Suppl. 1, 75-80.

33 Judson FN, Sbarbaro JA, Tapy JM, Cohn DL. Tuberculosis screening: evaluation of a food handlers' program. Chest 1983; 83: 879-882.

34 Dasgupta K, Menzies D. Cost-effectiveness of tuberculosis control strategies among immigrants and refugees. Eur Respir J 2005; 25: 1107-1116.

35 Van den Brande $P$, Uydebrouck M, Vermeire $P$, Demedts M, the VGRT (Flemish Lung and Tuberculosis Association). Tuberculosis in asylum seekers in Belgium. Eur Respir J 1997; 10: 610-614.

36 Chemtob D, Leventhal A, Weiler-Ravell D. Screening and management of tuberculosis in immigrants: the challenge beyond professional competence. Int J Tuberc Lung Dis 2003; 7: 959-966.
37 French CE, Antoine D, Gelb D, Jones JA, Gilbert RL, Watson JM. Tuberculosis in non-UK-born persons, England and Wales, 2001-2003. Int J Tuberc Lung Dis 2007; 11: 577-584.

38 Lillebaek $\mathrm{T}$, Andersen AB, Dirksen A, Smith E, Skovgaard LT, Kok-Jensen A. Persistent high incidence of tuberculosis in immigrants in a low-incidence country. Emerg Infect Dis 2002; 8: 679-684.

39 Verver S, Bwire R, Borgdorff MW. Screening for pulmonary tuberculosis among immigrants: estimated effect on severity of disease and duration of infectiousness. Int $J$ Tuberc Lung Dis 2001; 5: 419-425.

40 Verver S, van Soolingen D, Borgdorff MW. Effect of screening of immigrants on tuberculosis transmission. Int J Tuberc Lung Dis 2002; 6: 121-129.

41 Falzon D, Infuso A, Aït-Belghiti F. In the European Union, TB patients from former Soviet countries have a high risk of multidrug resistance. Int J Tuberc Lung Dis 2006; 10: 954-958.

42 Matteelli A, Migliori GB, Cirillo D, Centis R, Girardi E, Raviglione MC. Multidrug-resistant and extensively drugresistant Mycobacterium tuberculosis: epidemiology and control. Expert Rev Anti Infect Ther 2007; 5: 857-871.

43 Migliori GB, Loddenkemper R, Blasi F, Raviglione MC. 125 years after Robert Koch's discovery of the tubercle bacillus the new XDR-TB threat. Is "science" enough to tackle the epidemic? Eur Respir J 2007; 29: 423-427.

44 Bothamley GH, Rowan JP, Griffiths CJ, et al. Screening for tuberculosis: the port of arrival scheme compared with screening in general practice and the homeless. Thorax 2002; 57: 45-49.

45 Carvalho AC, Saleri N, El-Hamad I, et al. Completion of screening for latent tuberculosis infection among immigrants. Epidemiol Infect 2005; 133: 179-185.

46 Sanchez MA, Blower SM. Uncertainty and sensitivity analysis of the basic reproductive rate: tuberculosis as an example. Am J Epidemiol 1997; 145: 1127-1137.

47 Rennie TW, Bothamley GH, Engova D, Bates IP. Patient choice promotes adherence in preventive treatment for tuberculosis. Eur Respir J 2007; 30: 728-735.

48 Berkel GM, Cobelens FG, de Vries G, Draayer-Jansen IW, Borgdorff MW. Tuberculin skin test: estimation of positive and negative predictive values from routine data. Int $J$ Tuberc Lung Dis 2005; 9: 310-316.

49 Moran-Mendoza O, Marion SA, Elwood K, Patrick DM, Fitzgerald JM. Tuberculin skin test size and risk of tuberculosis development: a large population-based study in contacts. Int J Tuberc Lung Dis 2007; 11: 1014-1020.

50 Cobelens FG, Egwaga SM, van Ginkel T, Muwinge H, Matee MI, Borgdorff MW. Tuberculin skin testing in patients with HIV infection: limited benefit of reduced cutoff values. Clin Infect Dis 2006; 43: 634-639.

51 Wang L, Tuner MO, Elwood RK, Schulzer M, Fitzgerald JM. A meta-analysis of the effect of Bacille Calmette Guerin vaccination on tuberculin skin test measurements. Thorax 2002; 57: 804-809.

52 Diel R, Loddenkemper R, Meywald-Walter K, Niemann S, Nienhaus A. Predictive value of a whole-blood IFN- $\gamma$ assay for the development of active TB disease. Am J Respir Crit Care Med 2008; 177: 1164-1170. 
53 Smieja MJ, Marchetti CA, Cook DJ, Snaill FM. Isoniazid for preventing tuberculosis in non-HIV infected persons. Cochrane Database Syst Rev 2000; 2: CD001363.

54 Ewer K, Millington KA, Deeks JJ, Alvarez L, Bryant G, Lalvani A. Dynamic antigen-specific T-cell responses after point-source exposure to Mycobacterium tuberculosis. Am J Respir Crit Care Med 2006; 174: 831-839.
55 Horsburgh CR. Priorities for the treatment of latent tuberculosis infection in the United States. $N$ Engl J Med 2004; 350: 2060-2067.

56 Demers C, McMurray JJ, Swedberg K, et al. Impact of candesartan on nonfatal myocardial infarction and cardiovascular death in patients with heart failure. JAMA 2005; 294: 1794-1798. 